\title{
Correction to: Development and clinical validation of inertial sensor-based gait- clustering methods in Parkinson's disease
}

An Nguyen ${ }^{1 *}$, Nils Roth ${ }^{1}$, Nooshin Haji Ghassemi ${ }^{1}$, Julius Hannink1, Thomas Seel ${ }^{3}$, Jochen Klucken², Heiko Gassner ${ }^{2}$ and Bjoern M. Eskofier ${ }^{1}$

\section{Correction to: J Neuroeng Rehabil 2019;16:77 https://doi.org/10.1186/s12984-019-0548-2}

The original article [1] contained an error whereby Fig. 6 contained a minor shading glitch affecting its presentation. This has now been corrected.

\begin{abstract}
Author details
${ }^{1}$ Machine Learning and Data Analytics Lab, Department of Computer Science, Friedrich-Alexander-University Erlangen-Nürnberg (FAU), Carl-Thiersch-Straße, 2b, 91052 Erlangen, Germany. ${ }^{2}$ Department of Molecular Neurology, University, Hospital Erlangen, Friedrich-Alexander University Erlangen-Nürnberg (FAU), Schwabachanlage 6, 91054 Erlangen, Germany. ${ }^{3}$ Control Systems Group, Department of Electrical Engineering and Computer Science, Technische, Universität Berlin (TUB), Einsteinufer 17, 10587 Berlin, Germany.
\end{abstract}

Received: 15 July 2019 Accepted: 15 July 2019

Published online: 26 July 2019

\section{Reference}

1. Nguyen A, Roth N, Ghassemi NH, Hannink J, Seel T, Klucken J, et al. Development and clinical validation of inertial sensor-based gait-clustering methods in Parkinson's disease. J Neuroeng Rehabil. 2019;16:77. https://doi. org/10.1186/s12984-019-0548-2.

\footnotetext{
* Correspondence: an.nguyen@fau.de

${ }^{1}$ Machine Learning and Data Analytics Lab, Department of Computer

Science, Friedrich-Alexander-University Erlangen-Nürnberg (FAU),

Carl-Thiersch-Straße, 2b, 91052 Erlangen, Germany

Full list of author information is available at the end of the article
}

(c) The Author(s). 2019 Open Access This article is distributed under the terms of the Creative Commons Attribution 4.0 International License (http://creativecommons.org/licenses/by/4.0/), which permits unrestricted use, distribution, and reproduction in any medium, provided you give appropriate credit to the original author(s) and the source, provide a link to the Creative Commons license, and indicate if changes were made. The Creative Commons Public Domain Dedication waiver (http://creativecommons.org/publicdomain/zero/1.0/) applies to the data made available in this article, unless otherwise stated. 